\title{
VIENERIŲ METŲ TRUKMĖS ALERGENŲ SPECIFINĖS IMUNOTERAPIJOS POVEIKIS ALERGINEI ASTMAI
}

\author{
Kamilè Porutyte் ${ }^{1}$, Laura Saudargaite் ${ }^{1}$, Laura Tamašauskiené2 ${ }^{2}$ Brigita Šitkauskiené2 \\ ${ }^{1}$ Lietuvos sveikatos mokslu universiteto Medicinos akademijos Medicinos fakultetas, \\ ${ }^{2}$ Lietuvos sveikatos mokslu universiteto Medicinos akademijos Imunologijos ir alergologijos klinika
}

Raktažodžiai: alergenų specifinè imunoterapija (ASIT), alerginis rinitas, alerginè astma.

\begin{abstract}
Santrauka
Alergine astma yra viena iš labiausiai pasaulyje paplitusių lètinių neužkrečiamųjų ligų. Net 60-78 proc. pacientų, sergančių šia liga, kartu serga ir alerginiu rinitu. Šiuolaikinis alerginio rinito gydymo būdas, galintis sumažinti ar pašalinti ligos simptomus ilgam laikui, yra alergenų specifinè imunoterapija (ASIT). Pastebèta, kad šis gydymas turi teigiamos įtakos ir alerginei astmai. Tyrimo tikslas - įvertinti sergančiųų alergine astma kartu su alerginiu rinitu vieneriu metų gydymo ASIT poveikị alerginès astmos eigai. Atliktas retrospektyvinis tyrimas, ị kurị itraukta 15 pacientu, sergančių alerginiu rinitu kartu su alergine astma, kuriems 2018-2019 m. buvo taikyta ASIT. Išanalizuoti pacientų duomenys: lytis, amžius, ASIT tipas, astmos kontrolès testo (AKT) balas ir inhaliuojamojo gliukokortikoido budezonido (ar ekvivalento) suminè paros dozé prieš ASIT paskyrimą ir po vienerių metų gydymo. Atlikto tyrimo rezultatai atskleide tendenciją, kad po vienerių metų alerginès astmos kartu su alerginiu rinitu gydymo ASIT, gerèja astmos kontrolè ir mažèja inhaliuojamujų gliukokortikoidų poreikis. Siekiant tiksliau ịvertinti gydymo veiksmingumą, reikètų atlikti didesnès imties ir ilgesnès trukmès prospektyvinius tyrimus.
\end{abstract}

\section{Itvadas}

Alerginè astma yra dažna lètinè liga, kurios paplitimas pasaulyje nuolat didèja [1]. Jau dabar pasaulyje šia liga serga apie 300 milijonų žmonių ir prognozuojama, kad 2025 metais ja sirgs 100 milijonų daugiau [2]. Mokslinèje literatūroje nurodoma, kad 60-78 proc. pacientų, sergančių alergine astma, kartu serga ir alerginiu rinitu [3]. Šios dvi ligos pasauliniu mastu yra labiausiai paplitusios lètinès neužkrečiamosios ligos [4]. Alerginè astma ir alerginis rinitas dažnai lemia prastesnę gyvenimo kokybę, sergančiūjų neịgalumą, didina mirtingumą ir sveikatos priežiūros išlaidas [4-7].

Alerginių ligų gydymas susideda iš alergeno vengimo ir simptominio gydymo, tačiau sunku išvengti kontakto su alergenu, ypač esant įsijautrinimui žiedadulkẻms ar gyvūnams, kai jų yra namuose. Medikamentinis gydymas, nors ir efektyvus, tačiau simptomus sumažina tik tam tikram laikotarpiui, o vaistai turi būti vartojami ilgą laiką. Be to, žmonès dažnai reguliariai nevartoja paskirtų vaistų [8-9]. Šiuolaikinis alerginių ligų gydymo būdas, galintis sumažinti ar pašalinti ligos simptomus ilgam laikui, yra alergenų specifinè imunoterapija (toliau - ASIT). Tai vienintelis gydymo būdas, galintis modifikuoti ligos eigą ir sumažinti įsijautrinimo naujiems alergenams riziką [2]. Skiriami du skirtingi ASIT taikymo būdai: poodinè (toliau - SCIT) ir poliežuvinè (toliau -SLIT) [2]. ASIT sukelia B ir T atminties ląstelių atsako pokyčius bei sustabdo putliujų ląstelių ir bazofilų aktyvaciją, todèl formuojasi ilgalaikè tolerancija alergenams ir išnyksta alergijos simptomai [10]. Klinikiniam efektui pasiekti ir išsaugoti ji po gydymo pabaigos, ASIT iprasta taikyti 3-5 metus $[2,11]$, tačiau gydymo trukmé gali būti ilgesne, priklausomai nuo klinikinès situacijos [2].

ASIT rekomenduojama asmenims, sergantiems vidutinio sunkumo arba sunkiu alerginiu rinitu, lengva arba vidutinio sunkumo astma, sukelta įkvepiamujų alergenų [2-12]. Remiantis 2020 metais paskelbtomis Pasaulinès astmos iniciatyvos (GINA) rekomendacijomis, SLIT rekomenduojama kaip papildoma gydymo priemone alerginiu rinitu bei iš dalies kontroliuojama alergine astma sergantiems asmenims, ịsijautrinusiems namų dulkių erkutems [13]. Atlikta daug klinikiniu tyrimų, kuriuose nustatyta, kad ASIT taikymas gali turèti teigiamą poveikị astmos eigai, nes pagerèja ligos kontrolè ir sumažèja vartojamų vaistų dozès $[2,14]$.

Tyrimo tikslas - įvertinti sergančiujų alergine astma kartu su alerginiu rinitu vienerių metų gydymo ASIT poveikị astmos eigai. 


\section{Tyrimo objektas ir metodai}

Atliktas retrospektyvinis tyrimas Lietuvos sveikatos mokslų universiteto (toliau - LSMU) ligoninès Kauno klinikų Imunologijos ir alergologijos klinikoje. Tyrimui atlikti buvo gauti LSMU bioetikos centro ir Kauno klinikų leidimai. I tyrimą buvo itraukti pacientai, sergantys alerginiu rinitu kartu su alergine astma ir gydyti ASIT 2018-2019 metais. Pacientų duomenys buvo renkami iš ambulatorinių asmens sveikatos dokumentų ir ligoninès informacinès sistemos. Analizuoti šie nuasmeninti pacientų duomenys: lytis, amžius, ASIT tipas, astmos kontrolès testo (toliau - AKT) balas ir inhaliuojamo gliukokortikoido budezonido (ar ekvivalento) suminé paros dozė prieš ASIT paskyrimą ir po vienerių metu gydymo. Statistinè analizè atlikta naudojant Microsoft Excel 2010 ir SPSS 26.0 programas. Kokybiniai duomenys pateikti absoliučiomis reikšmėmis ir procentais, kiekybiniai duomenys pateikiami mediana \pm interkvartilinis plotis. Tikrinant statistines hipotezes, pasirinktas reikšmingumo lygmuo $\mathrm{p}<0,05$.

\section{Tyrimo rezultatai}

2018-2019 m. ASIT buvo taikyta 15 pacientu, sergančių alerginiu rinitu kartu su alergine astma. Tiriamujų demografiniai duomenys ir skirtas gydymas pateikiami 1 lentelèje. 93 proc. tiriamujų buvo skirta poodinè ASIT. Didžiausią dali (60 proc.) sudarè namų dulkių erkių alergenai. Po vienerių metų gydymo vertinant AKT balo pokytị ir inhaliuojamojo

1 lentelè. Tiriamujų demografiniai duomenys ir skirtas gydymas

\begin{tabular}{|l|c|}
\hline Amžius, m \pm SN & $29,8 \pm 2,8$ \\
\hline Požymiai & $\mathrm{n}$ (proc.) \\
\hline Lytis: & $10(67)$ \\
Moterys & $5(33)$ \\
Vyrai & $14(93)$ \\
\hline ASIT taikymo forma: & $1(7)$ \\
Poodinė & \\
Poliežuvine & $9(60)$ \\
\hline ASIT alergenai: & $6(40)$ \\
Dulkių erkutės & \\
Pelèsių, šuns ar katės & \\
\hline
\end{tabular}

2 lentelè. AKT balo ir budezonido suminès paros dozès pokyčiai

\begin{tabular}{|l|c|c|}
\hline Rodiklis & Mediana & $\begin{array}{c}\text { Interkvartilinis } \\
\text { plotis (min-max) }\end{array}$ \\
\hline Astmos kontrolès testas & 20 & $9(14-23)$ \\
\hline $\begin{array}{l}\text { Astmos kontrolès testas } \\
\text { po 1 metų }\end{array}$ & 23 & $9(16-25)$ \\
\hline Budezonido paros dozė $(\mathrm{mcg})$ & 400 & $800(0-800)$ \\
\hline $\begin{array}{l}\text { Budezonido paros dozè }(\mathrm{mcg}) \\
\text { po 1 metų }\end{array}$ & 360 & $800(0-800)$ \\
\hline
\end{tabular}

gliukokortikoido budezonido (ar ekvivalento) suminės paros dozès pokytį, stebèta teigiama dinamika, tačiau statistiškai reikšmingo skirtumo nenustatyta (2 lentelè). Nepageidaujamų reakcijų gydymo metu dokumentuota nebuvo.

\section{Diskusija}

Tyrimas atskleidè tendenciją, kad vienerių metų trukmès gydymas ASIT teigiamai veikia alerginès astmos eigą - pagerina AKT rezultatus ir sumažina vartojamų inhaliuojamujų gliukokortikoidų poreikį. Šie rezultatai sutampa su kitų tyrimų duomenimis - atlikta metaanalizè, kurioje išanalizuoti 9 tyrimai, aprèpę 441 astma sergantị vaiką, atskleidè, kad astmos simptomų ir vartojamų vaistų dozių sumažejjimas buvo reikšmingai didesnis taikant gydymą SLIT, nei placebu [2]. Atsitiktinių imčių klinikiniame tyrime, kuriame dalyvavo 146 tiriamieji, nustatytas statistiškai reikšmingas pacientų, vartojusių dideles inhaliuojamujų gliukokortokoidų dozes (180000 TU), suminès paros dozès sumažejimas, paskyrus gydymą ASIT [15]. Šio tyrimo metu stebètas ir astmos kontrolès testo rezultatų pagerejjimas [15]. Atlikta klinikinių tyrimų sisteminė apžvalga atskleidè, kad SCIT ir SLIT efektyviai sumažino astmos simptomus ir vartojamų medikamentų kiekį, lyginant su simptominiu gydymu ir placebu [16]. Kitas atliktas tyrimas, kurio metu suaugusiems asmenims buvo skiriamas gydymas SLIT namų dulkių erkių alergenais, atskleide, kad šis gydymas statistiškai reikšmingai sumažina vidutinès arba sunkios astmos paūmèjimo riziką, lyginant su placebo grupe [17].

Remiantis mūsų tyrimo duomenimis, pacientams dažniausiai taikyta ASIT namų dulkių erkių alergenais. Šis alergenas yra vienas dažniausių visame pasaulyje. Kinijoje atliktame epidemiologiniame tyrime nustatyta, kad pacientams, sergantiems alerginiu rinitu ir (arba) astma, dažniausias nustatytas ịsijautrinimas namų dulkių erkėms [18]. Nurodoma, kad ịsijautrinimas namų dulkių erkių alergenams nustatytas apie 10 proc. visos populiacijos ir net 90 proc. sergančiujų alergine astma [9].

Beveik visiems ị mūsų tyrimą ịtrauktiems pacientams buvo taikoma SCIT ir tik vienam - SLIT, todèl gydymo efektyvumo tarp skirtingų ASIT formų ịvertinti nepavyko, tačiau atliktos sisteminès apžvalgos ir metaanalizès įrodè abiejų šių ASIT formų efektyvumą, gydant daug metų trukusias ir sezonines alergines kvėpavimo takų ligas $[2,19]$. Mokslinèje literatūroje nurodoma, kad SCIT dažnai yra efektyvesnè, be to, pastebèta, kad astma sergančių vaikų gydymui taikant SCIT, greičiau pasiekiamas efektas [19]. Neseniai atliktoje apžvalgoje, lyginant SLIT ir SCIT efektyvumą gydant vaikų alerginę astmą, analizuoti 42 tyrimai ir nustatyta, kad SCIT reikšmingai sumažino namų dulkių erkių ir žiedadulkių sukeltus simptomus. Taip pat nustatyta, kad SLIT labiau su- 
mažino švokštimą, o SCIT efektyviau mažino kosulị [2]. S. Durham ir kolegos, ištyrę 106 pacientus, sergančius vidutinio sunkumo ir sunkiu sezoniniu alerginiu rinitu, kuriems buvo taikytas gydymas SLIT, SCIT arba placebu dvejus metus, nustatè, kad SCIT efektyviau sumažino slogos simptomus, tačiau SLIT grupejje ženkliau sumažejo alergijos simptomus mažinančių vaistų poreikis [20].

Mūsų tyrime nepageidaujamų ASIT reakcijų nebuvo dokumentuota. Panašūs rezultatai stebimi ir kitų autorių publikacijose - viename 3 metu trukmès atsitiktiniu imčių prospektyviniame tyrime, kuriame dalyvavo 48 vaikai, sergantys alergine astma ar alerginiu rinitu, gydomi SLIT arba SCIT namų dulkių erkių alergenais, nepageidaujamų reakcijų palaikomosios gydymo fazès metu nebuvo stebèta, tačiau ịvadinès fazès metu stebètos dvi sisteminès reakcijos, skiriant SCIT [21]. Labai sunkios sisteminès reakcijos pasitaiko 1 iš milijono SCIT injekcijų [16]. Mirtinos reakcijos, susijusios su ASIT, labai retos: JAV registruotas 1 mirties atvejis iš 2,5 milijonų, susijęs su SCIT skyrimu, o Europoje neužregistruota nei vieno tokio atvejo per pastaruosius 30 metų [16]. SCIT susijusi su didesne vietinių ir sisteminių nepageidaujamų reakcijų rizika, todèl šis gydymas taikomas tik sveikatos priežiūros įstaigose, o SLIT yra saugesnè, nepageidaujamų reakcijų rizika mažesnè, tad gali būti vartojama namuose $[19,22]$. M. Schiappoli ir kolegų Italijoje atliktame tyrime ištyrus 1738 pacientus, pastebèta, kad sisteminès reakcijos šiek tiek dažnesnès pacientams, sergantiems alerginiu rinitu su alergine astma, negu vien tik alerginiu rinitu [23]. R. Mösges ir bendraautorių metaanalizès išvadose nurodoma, kad gydant žiedadulkių arba namų dulkių erkių ASIT pacientus, kurie serga rinokonjunktyvitu ir alergine astma arba jos nesant, nebuvo reikšmingo medikamento saugumo ir tolerancijos skirtumo, lyginant su placebu [24].

\section{Išvados}

1. Alerginè astma ir alerginis rinitas yra dažnos lètinès ligos, neigiamai veikiančios gyvenimo kokybę, todẻl svarbu, kad skiriamas gydymas būtų efektyvus, saugus ir patogus pacientui.

2. Atlikto tyrimo rezultatai atskleidè tendenciją, kad po 1 metų alerginès astmos kartu su alerginiu rinitu gydymo ASIT, gerèja astmos kontrolè ir mažejja inhaliuojamujuç gliukokortikoidų poreikis, tačiau siekiant tiksliau įvertinti gydymo veiksmingumą, reikètų atlikti didesnès imties ir ilgesnès trukmès prospektyvinius tyrimus.

\section{Literatūra}

1. Asthma. https://www-nhlbi-nih-gov.ezproxy.dbazes.lsmuni.lt/ health-topics/asthma

2. Tsabouri S, Mavroudi A, Feketea G, Guibas GV. Subcutaneous and sublingual immunotherapy in allergic asthma in children. Front Pediatr 2017;5:1-9.

https://doi.org/10.3389/fped.2017.00082

3. Bunupuradah T, Siriaksorn S, Hinds D, Shantakumar S, Mulgirigama A, Aggarwal B. A survey of management practices in coexistent allergic rhinitis and asthma (Asia-pacific survey of physicians on asthma and allergic rhinitis): results from Thailand. Asia Pac Allergy 2019;9(3):e24.

https://doi.org/10.5415/apallergy.2019.9.e24

4. Eiringhaus K, Renz H, Matricardi P, Skevaki C. Componentresolved diagnosis in allergic rhinitis and asthma. J Appl Lab Med 2019;3(5):883-98.

https://doi.org/10.1373/jalm.2018.026526

5. Nurmagambetov T, Khavjou O, Murphy L, Orenstein D. Statelevel medical and absenteeism cost of asthma in the United States. J Asthma 2017;54(4):357-370. https://doi.org/10.1080/02770903.2016.1218013

6. Dharmage SC, Perret JL, Custovic A. Epidemiology of asthma in children and adults. Front Pediatr 2019;7:1-15. https://doi.org/10.3389/fped.2019.00246

7. Sikorska-Szaflik H, Sozańska B. Quality of life in allergic rhinitis - children's and their parents' perspective in polish urban and rural population. Health Qual Life Outcomes 2020;18(1):1-8. https://doi.org/10.1186/s12955-020-01315-1

8. Klimek L, Bachert C, Pfaar O, Becker S, Bieber T, Brehler R, et al. ARIA guideline 2019: treatment of allergic rhinitis in the German health system. Allergo J Int 2019;28(7):255-76. https://doi.org/10.1007/s40629-019-00110-9

9. Li L, Qian J, Zhou Y, Cui Y. Domestic mite-induced allergy: causes, diagnosis, and future prospects. Int J Immunopathol Pharmacol 2018;32(299). https://doi.org/10.1177/2058738418804095

10. Akdis CA, Akdis M. Mechanisms of allergen-specific immunotherapy and immune tolerance to allergens. World Allergy Organ J 2015;8(1):1-12.

https://doi.org/10.1186/s40413-015-0063-2

11. Guideline on allergen-specific immunotherapy in IgE- mediated allergic diseases. Allergo J Int 2014;23(8):282-319.

12. Jutel M, Agache I, Bonini S, Burks AW, Calderon M, Canonica $\mathrm{W}$, et al. International consensus on allergen immunotherapy ii: mechanisms, standardization, and pharmacoeconomics. J Allergy Clin Immunol 2016;137(2):358-68.

https://doi.org/10.1016/j.jaci.2015.12.1300

13. Global initiative for asthma: global strategy for asthma management and prevention. J Allergol Clin Immunol 2020;36(6):685704. https://ginasthma.org/wp-content/uploads/2020/04/GINA2020-full-report_final-_wms.pdf

14. EAACI guideline on allergen immunotherapy - allergic asthma. Allergy 2017;6:5-9. https://www.eaaci.org/documents/AIT/ Allergic_asthma_AIT_03_06_17.pdf

15. Jutel M, Rudert M, Kreimendahl F, Kuna P. Efficacy and to- 
lerability of a house dust mite allergoid in allergic bronchial asthma: a randomized dose-ranging trial. Immunotherapy 2018;10(13):1149-61.

https://doi.org/10.2217/imt-2018-0087

16. Dominguez-Ortega J, Delgado J, Blanco C, Prieto L, Arroabarren E, Cimarra M, et al. Specific allergen immunotherapy for the treatment of allergic asthma: a review of current evidence. J Investig Allergol Clin Immunol 2017;27:1-35.

https://doi.org/10.18176/jiaci.0149

17. Virchow JC, Backer V, Kuna P, Prieto L, Nolte H, Villesen HH, et al. Efficacy of a house dust mite sublingual allergen immunotherapy tablet in adults with allergic asthma: a randomized clinical trial. J Am Med Assoc 2016;315(16):1715-25. https://doi.org/10.1001/jama.2016.3964

18. Li J, Sun B, Huang Y, Lin X, Zhao D, Tan G, et al. A multicentre study assessing the prevalence of sensitizations in patients with asthma and/or rhinitis in China. Allergy Eur J Allergy Clin Immunol 2009;64(7):1083-92.

https://doi.org/10.1111/j.1398-9995.2009.01967.x

19. Pelaia C, Vatrella A, Lombardo N, Terracciano R, Navalesi P, et al. Biological mechanisms underlying the clinical effects of allergen-specific immunotherapy in asthmatic children, Expert Opin Biol Ther 2018;18(2):197-204.

https://doi.org/10.1080/14712598.2018.1402003

20. Scadding GW, Calderon MA, Shamji MH, et al. Effect of 2 years of treatment with sublingual grass pollen immunotherapy on nasal response to allergen challenge at 3 years among patients with moderate to severe seasonal allergic rhinitis: the GRASS randomized clinical trial. JAMA 2017;317(6):615-625.

https://doi.org/10.1001/jama.2016.21040

21. Karakoc-Aydiner E, Eifan AO, Baris S, Gunay E, Akturk E, Akkoc T, et al. Long-term effect of sublingual and subcutaneous immunotherapy in dust mite-allergic children with asthma/ rhinitis: a 3-year prospective randomized controlled trial. J Investig Allergol Clin Immunol 2015;25(5):334-42.

22. Elliott J, Kelly SE, Johnston A, Skidmore B, Gomes T, Wells GA. Allergen immunotherapy for the treatment of allergic rhinitis and/or asthma: an umbrella review. C Open 2017;5(2):E373-85.

https://doi.org/10.9778/cmajo.20160066

23. Schiappoli M, Ridolo E, Senna G, Alesina R, Antonicelli L, Asero R, Costantino MT, Longo R, Musarra A, Nettis E, et al. A prospective Italian survey on the safety of subcutaneous immunotherapy for respiratory allergy. Clin Exp Allergy 2009;39:1569-1574.

https://doi.org/10.1111/j.1365-2222.2009.03286.x

24. Mösges R, Valero Santiago A, Allekotte S, Jahed N, Astvatsatourov A, Sager A, et al. Subcutaneous immunotherapy with depigmented-polymerized allergen extracts: a systematic review and meta-analysis. Clin Transl Allergy 2019;9(1):1-15. https://doi.org/10.1186/s13601-019-0268-5

\section{EFFECT OF ALLERGEN SPECIFIC IMMUNOTHERAPY IN PATIENTS WITH ASTHMA AFTER ONE YEAR TREATMENT \\ K. Porutytè, L. Saudargaitė, L. Tamašauskienè, B. Šitkauskienè}

Keywords: allergen specific immunotherapy (ASIT), allergic rhinitis, allergic asthma.

Summary

Allergic asthma is one of the most common chronic non-contagious disease globally. This disease is diagnosed together with allergic rhinitis in $60-78 \%$ cases. Allergic rhinitis can be treated by allergen specific imunotherapy (ASIT), which changes immune response to allergen and may decrease symptoms. There are evidences that ASIT can have positive effect on allergic asthma. The aim of this study was to evaluate impact of ASIT on allergic asthma for patients having both allergic rhinitis and allergic asthma after one year of treatment. Retrospective study was conducted and 15 patients with allergic rhinitis and allergic asthma, who were treated by ASIT in 2018-2019 were recruited. Patients data were analyzed: gender, age, form of ASIT, result of asthma control test (ACT) and total daily dose of inhaled glucocorticoid budesonide (or equivalent) before treatment and after one year of ASIT prescription. The results revealed a tendency, that control of asthma was better and need of inhaled glucocorticoids decreased one year after prescribing ASIT compared with baseline, but in order to evaluate the efficacy of treatment more precisely a larger pool and a longer duration prospective studies should be performed

Correspondence to: kamileporutyte@gmail.com

Gauta 2020-05-14 